\title{
Evaluating Cultural Authenticity in Multicultural Picture Books: A Collaborative Analysis for Diversity Education
}

EunYoung Yoo-Lee, Lauren Fowler, Denice Adkins, Kyung-Sun Kim, and Halima N. Davis

\begin{abstract}
This study examines cultural authenticity reflected in multicultural picture books. Specifically, this study attempts to reframe issues surrounding the topic of cultural authenticity based on a systematic and empirical analysis of picture books that represent three different ethnic groups: African Americans, Asian Americans, and Hispanic Americans. A total of forty-five systematically selected picture books that represent fifteen books per ethnic group were selected and evaluated by multiple reviewers who were insiders of the culture. A coding scheme was developed to evaluate each book in terms of profile of major and minor characters, settings of the story, stereotypical features, and cultural authenticity. An in-depth evaluation of all selected books was added by a team of three reviewers in order to validate the results of the coded analysis. This study aims to shed light on library youth services and diversity education in a society with increasing ethnic diversity.
\end{abstract}

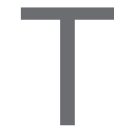

he issue of cultural authenticity in children's literature is one of contention and complexity. It is a topic that seems to generate ongoing debates, elicit strong cultural emotions, and involve a wide range of different perspectives from those who are involved in creating, teaching, and studying children's books (Bishop 2003). It is also a topic that gains more attention as the US population becomes increasingly diverse, since it reflects on topics such as the social responsibility of authors, the role of imagination and experience in writing for children, cultural sensitivity and values, authenticity of content and image, and ideological underpinnings (Short and Fox 2003).

This study examines the issue of cultural authenticity reflected in multicultural picture books in order to provide a new direction for diversity education for children. Specifically, it

The project was made possible by an American Library Association Diversity Research Grant. The authors would like to thank all the reviewers of the picture books for their valuable contributions.

Library Quarterly: Information, Community, Policy, vol. 84, no. 3, pp. 324-347. (C) 2014 by The University of Chicago. All rights reserved. $0024-2519 / 2014 / 8403-0005 \$ 10.00$

324 
attempts to reframe issues surrounding the topic of cultural authenticity based on a systematic and empirical analysis of picture books that represent three different ethnic groups: African Americans, Asian Americans, and Hispanic Americans. Central to the debates about cultural authenticity is another hot topic: diversity education or multiculturalism. Consistent with the approach of Mingshi Cai and Rudine S. Bishop (1994), this study understands multicultural literature as a pedagogical construct rather than a literary term, and the issue of cultural authenticity gains greater significance in light of the impact of literature on the lives of readers. Given these understandings about the relationship between cultural authenticity and multiculturalism and rapidly increasing diverse populations in our country, it will be important to assess to what extent the multicultural picture books reflect these changes.

This study aims to shed light on library youth services and diversity education in a society with increasing ethnic diversity. Using cultural authenticity as a criterion for evaluating multicultural picture books, the following research questions will be answered:

1. To what extent do children's picture books depict cultural authenticity via texts and illustrations?

2. How can cultural authenticity be understood with relation to nonstereotyping and cultural accuracy?

\section{Research about Cultural Authenticity}

\section{Defining Cultural Authenticity}

Cultural authenticity in picture books is essential to the success of multicultural education. Authentic books "allow young children opportunities to develop their understanding of others, while affirming children of diverse backgrounds" (Mendoza and Reese 2001). While scholars generally agree on the importance of exposing children to culturally authentic books (Barksdale-Ladd and Hefflin 2001; Mendoza and Reese 2001; Nilsson 2005; Jewett 2011), they have not reached a consensus on how to define "cultural authenticity."

Though Violet Harada (1995) assessed the cultural authenticity of Asian American picture books, she did not provide a specific definition of authenticity. She did, however, provide a list of criteria that guided her analysis: the absence of stereotypes, derogatory language, and parodied speech; accurate illustrations and historical or cultural information; and a proactive role for Asian American characters. Weimin Mo and Wenju Shen $(1997,86)$ question whether "authenticity equals nonstereotyped portrayals, positive images, lack of derogatory language, accurate historical information and cultural details, and realistic illustrations all put together." They argue that cultural authenticity comprises cultural values, not simply cultural facts. While not all members of a culture share similar values, when the themes and beliefs conveyed in a book "can be accommodated inside the range of values acceptable within that social group," it may be considered culturally authentic (Mo and Shen 1997, 87). 
An edited volume by Dana L. Short and Kathy G. Fox (2003) addresses the complexity of cultural authenticity in children's literature. In their introduction, the editors describe their search for a specific definition of cultural authenticity, culminating in a decision that "cultural authenticity cannot be defined, although 'you know it when you see it' as an insider reading a book about your own culture" (Short and Fox 2003, 4). The authors of the chapters seem to agree that there is "no formula or prescription for culturally authentic" children's books (Bishop 2003, 30; Guevara 2003; Rochman 2003). This lack of a clear definition for cultural authenticity complicates evaluation of picture books, although some authors have developed guidelines to assist parents, schools, and libraries in selecting authentic books.

In order to use cultural authenticity as a criterion for evaluation, it was necessary to choose a concrete definition. For the purpose of this study, cultural authenticity comprises not only the absence of stereotypes but also the presence of values consistent with a particular culture and the accuracy of cultural details in text and illustrations. The operationalization of this definition was informed by previous studies of African American, Asian American, and Hispanic American picture books. The following sections review how the previous studies in different ethnic groups approached the topic of cultural authenticity.

\section{Cultural Authenticity in African American Picture Books}

Mary Alice Barksdale-Ladd and Bena R. Hefflin (2001) combined their own experiences with children's literature, the recommendations of teachers, and the work of Rudine S. Bishop (1997) to develop criteria for good African American children's literature. They argue that in addition to possessing general characteristics of high-quality children's literature, such as vivid language and worthy themes, African American children's literature should meet additional standards. These criteria include well-developed characters in realistic situations, accurate representation of African American dialect, authentic illustrations of settings and characters (including variety in African Americans' skin color), and accurate information. The authors discuss their evaluation of one high-quality nonfiction picture book, Duke Ellington: The Piano Prince and His Orchestra, and provide an annotated bibliography of twenty-six titles that meet their selection criteria.

Emily Daly $(2004,5)$ evaluates the "cultural relevance to and sensitive depiction of" African Americans in twelve picture books published from 1962 through 2004. Daly's methodology, including how she selected the twelve books, is unclear. Daly found all twelve books to be culturally sensitive and appealing to African American children: each book "works to depict honestly and accurately the lives and experiences of the African Americans who read them" (Daly 2004, 15). Daly does mention the poor state of African American children's literature but does not explicitly address why her sample is not representative of the general situation. 
Wendy M. Smith-D’Arezzo and Margaret Musgrove's 2011 study looked for hidden messages in twenty-three picture books with black characters, published between 2000 and 2004. Regardless of the author's intentionality, the implicit racism in many of these stories "with exposure over time can work its way into children's belief systems" (Smith-D'Arezzo and Musgrove 2011, 196). Smith-D'Arezzo and Musgrove found negative hidden messages in eight of the books, including illustrations that reinforce stereotypes of blacks as being unintelligent or the inappropriate use of the word "gang" to refer to a group of boys. However, not all implicit messages are negative: ten of the twenty-three books had positive hidden messages, such as the encouragement to love writing and the presence of a positive black icon in Visiting Langston. The authors also found that their different cultural backgrounds affected how they responded to several books, leading to a recommendation that evaluation of books should incorporate the perspectives of colleagues and children from various racial groups.

\section{Cultural Authenticity in Asian American Picture Books}

Harada (1995) analyzed the authenticity of thirty-five Asian American picture books published between 1983 and 1993. She found that 90 percent of the books featured nonstereotyped characters and all were free of derogatory language. All books accurately conveyed historical details, although less than 70 percent authentically represented cultural information (Harada 1995, 141). Illustrations of characters were realistic in approximately 80 percent of the books sampled. Harada also found that non-Asian authors and illustrations performed as well as their Asian counterparts in accurately depicting characters and cultural details.

In their contribution to Short and Fox's (2003) edited volume, Mo and Shen echo their conviction, first articulated in their 1997 article, that "accuracy is not enough" (Mo and Shen 2003, 198). Some cultural details may be accurately portrayed but not authentic - such as the depiction of bound feet in the 1939 children's book Mei Li. While many Chinese women still had bound feet in 1939, after the 1911 revolution "people in China have viewed bound feet as a symbol of women's humiliated past. . . . Since the deformation of the feet could not be reversed, people held a cultural attitude of either paying no attention or avoiding mention of them" (Mo and Shen 2003, 202). The illustrations in this book therefore failed to meet Mo and Shen's value-based criteria for authenticity. The authors find that a number of other Asian American books fail to distinguish between cultural and historical facts, like the Confucian moral code and "people's actual attitudes" toward those experiences.

Junko Yokota (2009) explores the range and authenticity of Asian American characters in children's books. While there has been a significant increase in the representation of Asian Americans during the past two decades and a transition away from "long ago and far away" tales to contemporary stories, the author notes that there are still problems to be resolved (Yokota 2009, 15). Books that perpetuate stereotypes and an assimilation ideology are still being published. Existing picture books also fail to represent the full range of cultural ex- 
periences and histories, instead repeatedly exploring the same themes. Furthermore, relatively few picture books have Asian characters who are not of Chinese, Japanese, Korean, or Indian descent. Yokota's review of books is unsystematic, but the issues in representation identified by Yokota confirm the need for continuing evaluation of multicultural children's books.

\section{Cultural Authenticity in Hispanic American Picture Books}

Jean Mendoza and Debbie Reese (2001) critique two picture books with Mexican American protagonists and identify issues in selecting culturally authentic children's literature. For each book, the authors summarize the plot and examine the text and illustrations to determine how Mexican American culture is represented. While A Day's Work seemed sympathetic to its characters, it perpetuated stereotypes of Mexican American men as manual labors who are "none too bright" (Mendoza and Reese 2001). Alternately, the authors argue that A Gift from Papa Diego provides a positive and authentic picture of Mexican American family relationships. They note, however, that no single book can represent the complex, multidimensional experiences of a culture.

Rosalinda B. Barrera and Ruth E. Quiroa (2003) focus on a single criterion for Hispanic American children's literature: the authentic use of Spanish. The authors examine the usage of Spanish words and phrases in picture books published in the United States between 1995 and 2000, highlighting examples of unrealistic and realistic uses of kinship terms, culinary terms, and ethnographic terms for places. Based on their findings, they suggest that Spanish terms should be used judiciously and deliberately to evoke themes and highlight cultural differences, rather than tossed in to add exotic flavor. The authors also recommend contextual and nonliteral translation methods over literal and near-literal methods that create unrealistic patterns of speech and language.

Nina L. Nilsson (2005) provides an excellent synthesis of twenty-one content analysis studies on Hispanics in children's literature, conducted between 1966 and 2003. While differences in book samples, definitions of Hispanic, and research questions complicate the task of making comparison across studies, Nilsson was able to identify a few trends. Several studies report an overall increase in the number of books with Hispanic characters but note that this increase has not kept pace with the growing Hispanic population in the United States, leaving them "grossly underrepresented" in the literature (Nilsson 2005, 544). The authenticity of these books varies among the different Hispanic subgroups: books about Mexican American characters tend to better reflect contemporary issues and recent improvements in socioeconomic status, as opposed to books about Puerto Ricans. Stereotyping is also more common in the portrayal of female characters, who are often "submissive and one dimensional" (Nilsson 2005, 545). Given these findings, Nilsson emphasizes the need for continuing reevaluation of Hispanic portrayal in picture books. 
With the exception of Nilsson's meta-analysis, most previous studies of cultural authenticity have analyzed a relatively limited number of picture books and have not clearly explained how they chose those books. These studies also tend to focus on books about a single cultural group. By analyzing several books from three cultural groups, we hope to provide a more complete picture of the current state of cultural authenticity in picture books.

\section{Methods}

\section{Selection of Books}

Three major ethnic groups in the United States were identified for the study. They were (1) African Americans, (2) Asian Americans, and (3) Hispanic Americans. A total of fortyfive picture books that account for fifteen books per ethnic group were selected. Books published between 2000 and 2009 were selected to meet the currency of cultural authenticity. All selected books were available from local public and academic libraries.

\section{Selection Tools}

A couple of selection tools were employed to ensure a nonbiased systematic selection. The major tool used was NoveList. NoveList is an electronic readers' advisory resource (database) for children's and teens' fiction hosted by EBSCO. The searches were performed based on "subject" (e.g., African American, picture books) and set limit "publication year" after 2000 and sorted by "popularity." Popular titles are starred to indicate high demand. The popularity information is gathered from thousands of libraries and retail outlets nationwide and is based on over ten years' worth of ordering information received by Baker and Taylor. When you sort a list by popularity, titles displaying the same number of stars are ranked accordingly within the list from the highest level. Approximately thirty picture books for each ethnic group were selected using NoveList, which was two times more than the final selection. "Popularity" was used to select books that have been widely acquired by libraries and bookstores and thus are likely to be encountered by a broader audience of users, educators, and researchers. The potential impact of these titles on multicultural education is therefore greater than that of their less popular counterparts.

The second tool used was "ССВC Choices, 2000-2008." ССВC Choices is the annual best of the books recommended by librarians at the Cooperative Children's Book Center (CCBC). The $C C B C$ is a unique examination, study, and research library for children and young adults' literature, located in the University of Wisconsin-Madison. Each title identified through NoveList was checked in ССВС Choices, and the titles selected by both tools were filtered. In addition to these, Understanding Diversity through Novels and Picture Books (2007) was consulted as a third tool to ensure the quality and popularity of the books selected. In total, forty-five books (fifteen books per ethnic group) were selected (see the appendix). 
First Round: Content Analysis

In order to explore the issue of cultural authenticity in picture books representing each ethnic group, two coders per group, that is, six in total, were chosen. The criteria for the selection were these: insiders of the culture, one male and one female, and demonstrated interest or experiences in children's literature and/or librarianship. Specifically, the coders for African American books were one female and one male African American graduate student at a library school. The coders for Asian American books were a female IT professional with an MIS degree and a male who works at a higher education institute. They were foreign-born Chinese and Korean American. The coders for Hispanic American books were a female Hispanic American professional librarian and a male library assistant who work at public libraries. One was foreign born, and the other was born in the United States.

A coding scheme was developed and given to each coder for content analysis. The scope of the coding scheme includes title of the book, description of the major character, description of the minor character(s), setting, and stereotypical features and authentic/inauthentic elements. Specifically, when describing "major and minor characters," their names, demographics (e.g., gender and age), and social roles/relationships with others were coded. For the "setting," both geographic and historical contexts were considered. "Stereotypical features" and "cultural authenticity" were coded based on both texts and illustrations qualitatively. Coders determined whether stereotypical or culturally authentic features were depicted in each title and, if so, to what extent and how the title portrays them.

\section{Second Round: In-Depth Analysis}

Three new reviewers who are insiders of each of three cultures but who were not a part of the previous content analysis team were selected to analyze the books in depth. The African American books were reviewed by an African American raised in the United States, the Asian American books were reviewed by a foreign-born Korean American, and the Latino book reviewer was a bicultural Anglo and Mexican American woman. The second-level analysis used open coding to compare the first-round reviewers' analyses to the second-round reviewers' perceptions. Specifically, the reviewers read and evaluated the titles assigned to them independently, but roughly based on the coding scheme used for content analysis above, and then compared their findings with the results of content analyses done by other coders in order to validate them. They were asked to write an in-depth summary report based on their evaluation.

\section{Results}

\section{Summary of the Results Based on Content Analysis}

Table 1 summarizes profiles of major and minor characters in terms of gender, age, and social roles. Most of the major characters were school-age girls or boys rather than adults. In 


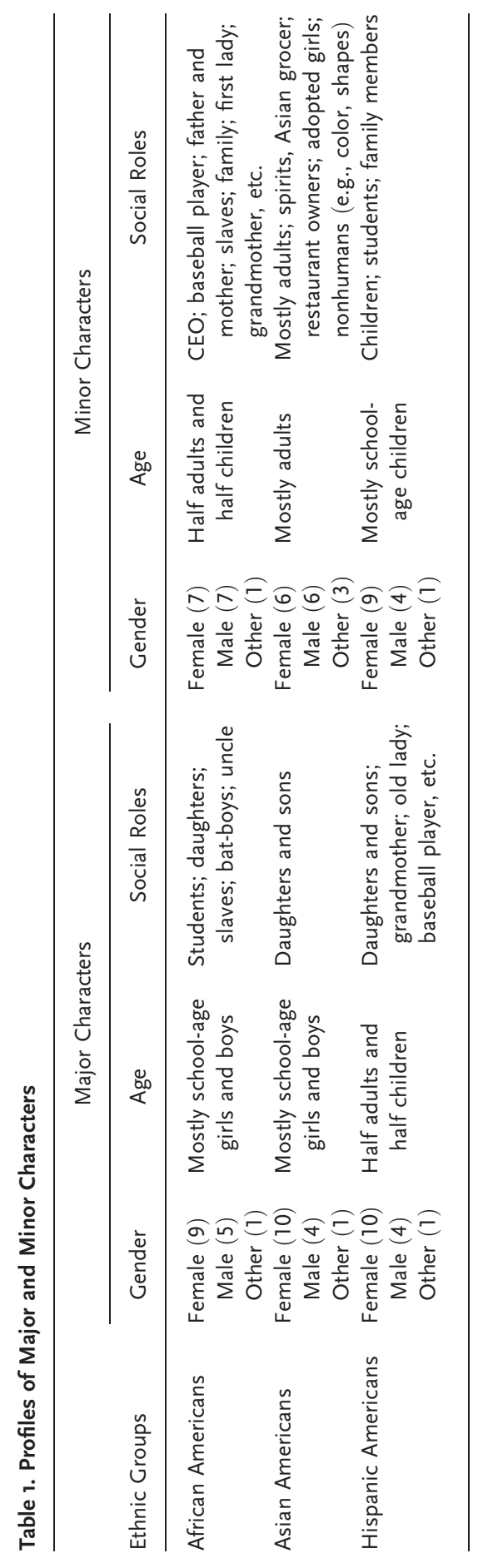


all three ethnic groups, more girls than boys were depicted as major characters. In general, the roles of major characters were described in the context of their families and schools. When adults were chosen as major characters, their roles were also described in the context of families.

While most major characters were school-age girls or boys, more adults than children were represented as minor characters in the titles selected. The roles of minor characters varied greatly from general family members (e.g., mother, father, grandmother, and student) to specific (e.g., CEO, baseball player, grocer, restaurant owner).

Table 2 summarizes the settings of the picture books. Settings in the picture books were coded by geographic locations, environment, special places or chronological times. While the majority of the Asian American and Hispanic American stories took place in contemporary times, about half of the African American picture books described historical settings such as a slave plantation and a 1915 New York subway project. African Americans were also illustrated in some special places such as jail, professional baseball locker room, or subway. Most African American and Hispanic American stories took place in inner cities or urban areas, but Asian Americans were primarily portrayed in suburban neighborhoods, especially Asian neighborhoods, or at special cultural events such as weddings and Chinese New Year.

Table 3 attempts to summarize stereotypical features and culturally authentic features in the sample picture books. In African American titles, coders agree that most books depict the culture authentically, although some overlap with negative stereotypical features of the

Table 2. Settings

\begin{tabular}{ll}
\hline Ethnic Groups & Settings \\
\hline African Americans & - Inner city/urban (about 50\%) \\
& - Special places: jail, pro baseball locker room, slave \\
plantation, subway & Contemporary times (9); Historical times (6) \\
- Mostly neighborhood (some Asian neighborhood) & in the United States \\
- Some Asian countries & - Special places: Asian grocery/restaurant \\
& - Special events: Fourth of July, Halloween, Chinese \\
& wedding, Chinese New Year \\
& - Mostly contemporary (13 out of 15) \\
- Mostly inner cities of Latin American neighborhood \\
(e.g., Harlem, NY; Bronx, NY; urban CA, etc.) \\
- Some in United States and countries of the culture \\
(country names identified in some stories) \\
- Mostly contemporary (14 out of 15)
\end{tabular}


culture. Some positive aspects are the importance of family and tradition, perseverance/ resilience, and appearance in illustration. Some negative aspects are single family home and "none of my business" mentality.

In Asian American titles, coders agree that the majority of the books depicted the culture authentically, even though some cultural details (e.g., cooking process and wedding ceremony) lacked authentic descriptions. Most books tried to portray important parts of Asian Americans' culture (e.g., traditional foods, customs, Chinese New Year, wedding). They also described some challenges that immigrant families face, including intergenerational conflicts/ gaps, and language/cultural differences. Three out of fifteen titles handled adoption stories. In general, most books portrayed Asian culture fairly positively; some stereotypical characteristics were found (e.g., hard-working, shyness, adoption).

In Hispanic American titles, coders agree that the majority of the books depicted the culture authentically. Positive aspects include extended family, family closeness, hard-working Hispanics, family-centered business, use of bright colors in illustrations, and recognizing diverse Hispanic descents. Negative aspects are incorrect translation of Spanish words and single parent home.

\section{In-Depth Analysis of Each Culture Based on Fifteen Picture Books African Americans}

The portrayal of African Americans in American culture has been a highly contentious debate for decades. Many painful stereotypes that permeate the general culture have trickled down into the world of children's literature. Further complicating the matter is the teetering balance between the promising growth in the publishing of children's books portraying African American characters (when there were so few in the recent past) and the disturbing lack of cultural authenticity displayed in many of these works. Many librarians, educators, and parents are pleased to have more choices of children's books with African American characters but are often surprised by the stereotypical themes and images that are still present in several works of children's literature today. This is not to say that there are not more accurate portrayals available. Several of the books chosen for the study were good examples of culturally authentic picture books. The difficulty comes in how to better assist youth services librarians, educators, and parents in choosing books that more accurately portray African Americans and how to encourage authors and illustrators to consider the effects their images and themes may have on African American children, as well as children from other cultures who are exposed to their works of literature.

The array of African American picture books included in the study was varied, and the titles are widely available in most public libraries. The first-round coders noted that some of the names chosen for main characters were associated with African American culture, though they did not specify which names they were referring to. The social roles of major characters 


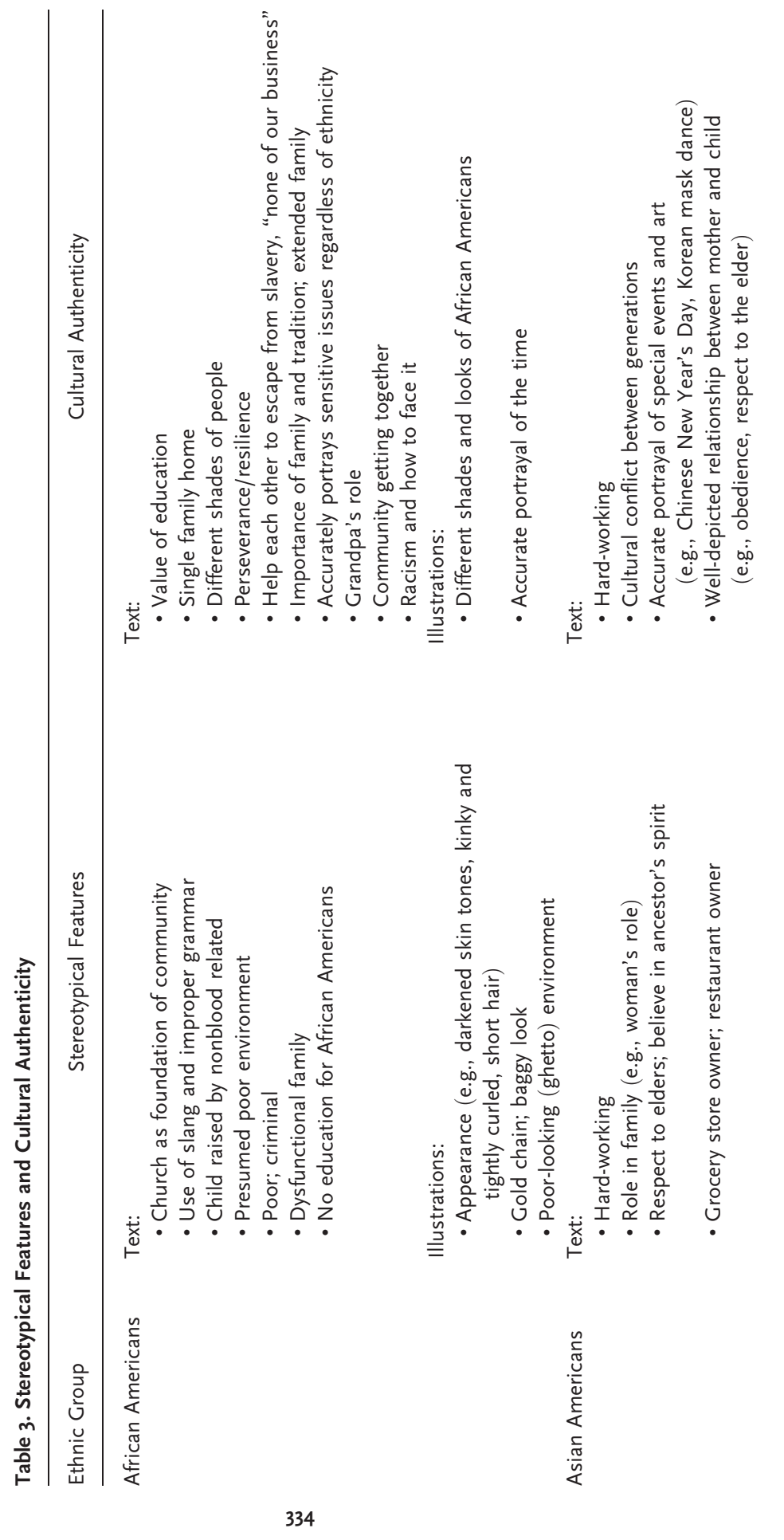



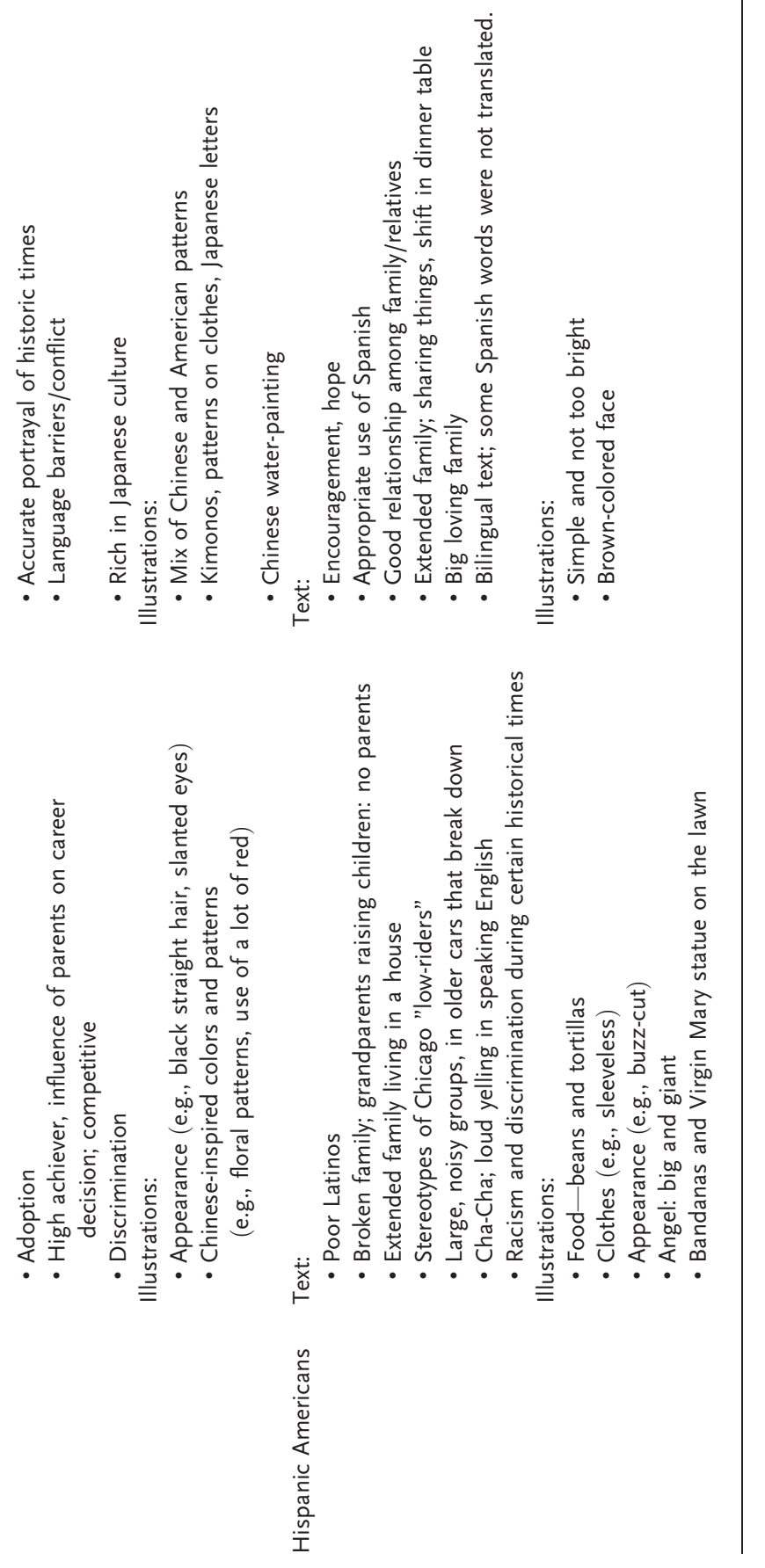

335 
in the stories were well described. For example, Daisy, the main character in Squashed in the Middle, was the middle child of three. Her perception of her role in the family, as well as the important role she actually held in her family, were brought to life through the author's vivid descriptions.

The books were divided evenly between contemporary times and the past, as well as between inner-city and rural or special settings. Some special settings in the books were a jail, a professional baseball locker room, a slave plantation, and the subway. It is interesting that half of the books selected for the study did not take place in modern times. This is sometimes an issue in African American children's literature. A large number of books selected for libraries and schools depict African Americans during slavery, reconstruction, and the civil rights era. Though these works of literature may portray characters accurately for the historical time period, they also serve to perpetuate a stereotypical view of African American characters as figments of the past or as characters that are only valid in their historical roles. It is difficult to balance the importance of educating our youth about the historical struggles of African Americans in American society while continuing to present modern characters that appeal to young readers because their experiences and appearance may mirror those of the reader.

Coders found approximately one-third of the selected books to include stereotypical elements. These elements included athleticism, rhythmic or musical attributes, lack of intelligence, poverty, loud or boisterous behavior, criminal elements, hostile attitudes, profound religious beliefs, loyalty to family, and dirty/filthy appearance or environment. The majority of these elements were found in the illustrations, but there were also examples of stereotypical speech found in the text of the books. In Hot Day on Abbot Avenue, many of the characters are portrayed with unruly and unkempt hair and exaggerated facial features (e.g., lips, teeth, and noses). The illustrations support the stereotype that African Americans have extremely large extremities, and nothing in the story seems to assert that not all African Americans look this way. In Yo Jo!, examples of stereotypes were found in both the illustrations and text. Jomar's neighborhood is depicted with trash and trash cans and graffitiscribbled walls. Every scene in the book contains graffiti and trash except in the scene containing an Asian restaurant. African Americans are depicted wearing hats turned backward and head rags; males wear earrings, gold chains ("bling bling"), and saggy pants. Jomar and his peers are portrayed as being rhythmic. There is frequent use of slang terms and abbreviated expressions when communicating with peers and the dropping of the 'ing' suffix at the end of words (e.g., s'up, zoomin'). Although some of the images displayed and slang terms or abbreviated expressions used in the books may represent a portion of African American youth, the stories that include these elements do nothing to dispel the myth that all African Americans look, speak, or behave the same way.

Elements of the books and or characters that were described by coders as culturally authentic included themes such as importance of family in African American culture, spe- 
cifically the central role of importance that mothers play in the family; single parent family; "None of our business" mentality; extended family; perseverance and resilience; importance of tradition; reverence for elders; family loyalty; value of education; and oral tradition. These themes were most evident in the text of the selected children's books. The overall analysis revealed that although the listed themes can be considered stereotypical, many are authentic to the African American experience. One book in particular, Visiting Day, took the issue of incarceration, which could be perceived as an attempt to perpetuate the stereotype of African American criminal behavior, but instead displayed cultural authenticity by providing a story that showed family loyalty and the new family traditions that are formed to support the incarcerated father and to hold the family together while he is gone. Similar approaches were applied to the portrayal of single parent households in many of the selected books. Coders reacted positively to the story, Squashed in the Middle, which was the only book that showed an African American family as a traditional two parent household. The father is described as an equal partner who shares the responsibility of taking care of the family. The illustrations of this book showed the parents wearing wedding rings and being affectionate with each other and their children. This book showed that not all African American families are single parent households. In many of the selected stories, culturally authentic elements were present along with negative stereotypes. This combination of authentic themes and stereotyped appearances may increase the difficulty of choosing books that accurately reflect the diversity of African American culture.

\section{Asian Americans}

Of the major cultural groups in the United States, Asian cultures or Asian Americans are the least represented in picture books. However, the representation of Asian culture in multicultural picture books has grown substantially since 1990, with a significant move away from exoticism, folklore, and historical fiction (Yokota 2009). Except for Landed, Sixteen Years in Sixteen Seconds, and a few books that did not identify geographic and chronological settings, most of the books reviewed in this study depicted Asian American cultures in the contemporary world.

However, the selected books did not represent the range of Asian countries and culture. The Chinese appear most frequently (ten books), followed by Koreans (four books) and Japanese (one book). As Yokota (2009) addressed, these three countries and India are most prominent in Asian American picture books. Other Asian countries, especially South Asian countries such as the Philippines and Vietnam, are underrepresented in children's books- $\mathrm{a}$ problem that must be remedied because there is no uniform Asian American culture. Individual Asian countries or groups each identify unique histories and cultural experiences, which should be reflected in a range of picture books. Although the majority of the books were set in the contemporary world, a few books such as Landed and Sixteen Years in Sixteen 
Seconds attempted to deliver the historical details of Asian American immigration based on true stories. Specifically, they depict some important historical experiences that may not be as prevalent in modern times but are still important to remember, such as difficulty getting into America and racial discrimination.

The overall analysis of coders reveals that the majority of the books include authentic rather than stereotyped depictions of characters, cultural details, and historical information in both text and illustrations. Derogatory language is absent, and standard English is used in all books. Stereotypes or subtle inaccuracies, however, are unavoidable. Stereotypical features of the Asian Americans portrayed in the selected fifteen titles were "grocery owners" in Cooper's Lesson and Apple Pie 4th of July, "gender roles" in Bee-bim Bop, and "passiveness/submissiveness" in Cooper's Lesson and Yoko Writes Her Name. In addition, some illustrations featured Asian Americans with exaggerated straight black hair and slanted eyes.

Although it is not necessarily negative, the stereotypes of Asians as high achievers and a competitive and hard-working race were featured in Sixteen Years in Sixteen Seconds and Apple Pie 4th of July. However, it is worth noting that these images were found in a historic book or tended to apply to the parent's generation. The former depicts the inspirational biography of Sammy Lee, who won the Olympic gold medal in 1948 in diving and who also became a medical doctor to follow his father's vision for him, while the latter describes first-generation Chinese-immigrant parents who open their Asian store every day except for Christmas. Both books included subtle intergenerational conflict between the parents and the children who were portrayed as main characters in the books.

Various aspects of cultures from everyday cooking to special holidays are accurately described in most of the books. For example, Bee-bim Bop describes the preparation of Bee-bim bop, a famous Korean dish, in detail with bright and playful illustrations. Although the overall description of the process of making Bee-bim bop is correct, the absence of pepper sauce that is needed to mix rice and vegetables can be noted as an example of inaccuracy. Also, the grandmother's hairstyle is a bit out of date. Bringing in the New Year and Uncle Peter's Amazing Chinese Wedding depict what Chinese Americans do on these two special days. Traditional New Year's Day activities are accurately described as "sweeping out the old year," "hanging the spring-happiness poems and luck sign," "eating dumplings and whole fish," and "playing firecracker." A traditional Chinese wedding ceremony is well depicted in Uncle Peter's Amazing Chinese Wedding. However, some inaccuracies such as a wedding cake, kissing in front of people, and wedding rings are noted as examples of cultural confusion, or perhaps cultural adaptation because the wedding happens in the United States. Colors, shapes, patterns, and clothes in the two Chinese books are culturally authentic and realistic.

Coders found that Asian virtues, "respect to the elderly" (e.g., grandparents and ancestors) and "respect to tradition/history," were extensively described in the selected titles. In some titles, such as Behind the Mask and Grandfather Counts, these virtues were presented as central 
themes, and authors and illustrators attempted to describe how these values were handed over to younger generations who immigrated to the United States. Specifically, Behind the Mask described and illustrated how a young Korean American boy smoothly interwove Western Halloween with Korean traditional culture, through his late grandfather's memorable traditional Korean mask dance costumes. Many other titles subtly integrated these traditional values in their stories as deeply rooted and agreed culture of Asia (i.e., Bee-bim Bop, Sixteen Years in Sixty Seconds, and Cooper's Lesson).

Cultural adaptation or acceptance is another important theme featured in several books. For example, Cooper's Lesson, Yoko Writes Her Name, and Grandfather Counts showed the process of overcoming language barriers and intergenerational gaps and described how the Asian American characters resolve their own problems as immigrants. Considering Asian Americans' relatively recent immigration history and diverse language groups and cultures compared to other ethnic groups in the United States, "cultural adaptation" or "cultural acceptance/ assimilation" is a valid theme that must be authentically portrayed in multicultural children's literature.

Adoption is a theme in three of the fifteen selected books. Of the three books, Every Year on Your Birthday and Just Add One More Chinese Sister were written and illustrated by outsiders of the culture, while My Mei Mei was written by an insider. All three stories described Chinese babies' adoption process into the United States accurately and handled adoption positively from the perspective of American families. However, as coders mentioned, the high percentage of adoption stories in Asian picture books, especially Chinese picture books, reinforced the stereotype of "high adoption rate" in some Asian countries.

\section{Hispanic Americans}

"The Latino culture," as such, does not exist. Latinos have heritage in many different countries and regions in North and South America, including islands. The shared feature is that their ancestors were indigenous peoples whose homelands were colonized by the Spanish and Portuguese. A Puerto Rican Latino has had a different life experience than a New York Latino, even if that New York Latino has Puerto Rican heritage. Both of those people would have different experiences from a fourth-generation Mexican American Latino raised in California. In order to see the full diversity of Latinos in the United States, we need multiple works describing multiple Latino populations. Latino picture books have a big job: they must simultaneously present a Latino culture to other Latino cultures and to non-Latinos as well, transmitting insider knowledge and acquainting outsiders with a new and different culture.

The selection of Latino-oriented children's books did this - to some degree. The books were generally set in the contemporary United States, with the exception of Roberto Clemente, which is set in the United States and Puerto Rico in the 1960s and early 1970s, and My 
Grandma/Mi Abuelita, which tells the story of a boy going from the United States to visit his grandmother in an unnamed tropical location. Settings were varied, reflecting the wide distribution of the Latino population nationwide. California appeared four times, and the New York metro area three times. Four books did not indicate a specific location, but in some of those books, the nature of either the text or the illustrations suggested a Mexican American community. Latino origins were overtly mentioned in only five books. Of those, three identified Mexican heritage, one Dominican Republic heritage, and one Puerto Rican heritage.

For the most part, coders did not see many stereotypes in individual books. Those they pointed out tended to be things like poverty, traditional foods, and stereotypical gender roles. These are most commonly found in illustrations, although text can play a role too. In the text of No Dogs Allowed, Iris mentions her mother cooking huge quantities of food, and the illustrations feature Iris's mother wearing both high heels and an apron. In the text of If the Shoe Fits, Rigo has a large family with several brothers and a sister, and this is portrayed primarily through the text. There was a certain tendency to romanticize the heritage communities. In My Grandma/Mi Abuelita, the family visits a grandmother who lives on a rustic island, and the illustrations of Puerto Rico in Roberto Clemente always featured a tropical, nonurbanized background. Beans feature in the illustrations of three different books, Let's Eat/A Comer!, If the Shoe Fits, and No Dogs Allowed. Some images do verge on stereotypical but may be culturally accurate. For instance, in My Little Car, a man driving a stereotypical lowrider talks to Teresa while she is driving her toy low-rider. The text accompanying this image is used to demonstrate regional slang and portrays the man as a sympathetic and supportive character.

The factors identified by coders as "cultural authenticity" were generally values (e.g., love of family, respect for elders, the value of hard work). These values are not as easily portrayed as stereotypes that can be pointed to and are generally depicted through text. Additional factors identified by coders as culturally authentic were images and text that ran counter to stereotypes. These included a mixed-race marriage (Oh, Brother), diverse occupations (e.g., woman as carpenter, stories featuring fathers as primary caregivers), and nuanced portrayals of Latino characters.

The value of hard work and perseverance is emphasized in several of the books. In The Bakery Lady, Mónica learns that baking isn't all fun. Tomasito in Featherless/Desplumado accepts that he cannot walk but learns that he can still succeed by redefining success. Lucy, of Sparky's Bark/El Ladrido de Sparky, exerts effort and conquers embarrassment to learn English. Teresa in My Little Car learns to maintain and care for her possessions.

Many stories feature a motif of respect for elders, and elders in return connecting younger generations to their culture. One instance has If the Shoe Fit's Rigo mentioning that he likes to hear his uncle's stories of Mexico, communicating Rigo's respect for his family her- 
itage and for his relative. In Nana's Big Surprise the child characters also indicate their desire to listen to older relatives telling stories of their lives in Mexico. Lucy in Little Mamá Forgets has memorized her grandmother's tales of Mexico.

Several of the books featured families providing for or caring for extended family members, from grandparents in The Bakery Lady caring for their grandchildren to Ruthie in A Box Full of Kittens providing company for her pregnant Aunt Juanita. Most frequently, a family supports a grandmother who lives with them (Little Mamá Forgets, Let's Eat, Nana's Big Surprise). This support portrays the value that Latinos place on maintaining family ties. Despite this, there were some stories in which the characters seemed to be isolated. Featherless features a family of two, father and son; My Feet Are Laughing has a divorced mother living with her two daughters; Oh, Brother makes no mention of extended family.

Despite the popular stereotype of Latino male machismo, fathers are often very affectionate and caring toward their children, and this shows in these books. We see two single father households, in Featherless/Desplumado and My Grandma/Mi Abuelita. Teresa, her father, and her grandfather work together in $M y$ Little Car. In My Feet Were Laughing, Sadie's father still plays an active role in her life even though her mother and father are divorced.

Of the books reviewed, half featured bilingual text and the other half featured some words in Spanish. A book with bilingual text usually features the English translation of the text on one page and the Spanish translation on the opposite page. Despite a few issues, coders found that the Spanish and English translations were correct and consistent, though some bilingual stories were not translated word for word, or used different words to get the same sense across. Bilingual books tend to feature the English language more prominently, either placing the English at the top of the page or in larger letters than the Spanish. $M y$ Grandma/Mi Abuelita provided a refreshing counterexample to this.

Books that featured English text supplemented with selected words in Spanish often had a glossary at the end of the story to translate those words. Generational language shifts mean that not all US Latinos speak Spanish. In the United States, heritage languages are generally lost by the third or fourth generation. This was not explicitly mentioned or dealt with in the body of Latino picture books being reviewed, but these books may be attempting to accommodate that trend.

\section{Discussion and Conclusion}

Despite the difficulty in identifying a clear definition for cultural authenticity, this study attempted to use cultural authenticity as a criterion for evaluating multicultural picture books in order to provide a new direction in diversity education for children. Specifically, the study provides a systematic and empirical analysis of a sample of forty-five picture books that represent three different ethnic groups - African Americans, Asian Americans, and Hispanic Americans - with a focus on the issue of cultural authenticity as portrayed in the books. 
The evaluation, based on two rounds of content analyses by nine coders, revealed a general consensus that most picture books selected for evaluation were culturally authentic overall. However, the analysis also indicates that various levels of stereotypical elements still exist in some text and illustrations. In Asian American and Hispanic American picture books, the presence of stereotypical elements does not seem to preclude cultural authenticity. In other words, the coders in these cultures consider some stereotypical features to be authentic. In many of the African American picture books, however, culturally authentic elements were depicted along with negative stereotypical features of the culture. These negative stereotypes may impede the transmission of culturally authentic themes - even when a positive theme is intended as the primary message of a book, it may be overpowered by a negative hidden message in the text or illustrations.

The two rounds of evaluation indicate that cultural authenticity is a higher-level concept that embraces nonstereotyping and cultural accuracy. Our definition of cultural authenticity, focusing on the presence of values consistent with a particular culture and the accuracy of cultural details in text and illustrations, was borne out by the analysis. Although a coding scheme was used as an initial evaluation tool to explore several related themes such as stereotypes, the accuracy of text and illustrations, and cultural authenticity, the second round analysis demonstrated that these concepts need to be evaluated in concert, especially when stereotypical and authentic features coexist in a single book. The reviewers who were insiders of each culture were able to describe to what extent stereotypical features counteract cultural authenticity and to what extent accurate cultural facts can contribute to the overall cultural authenticity of a book.

In spite of the lack of consensus on the definition of cultural authenticity, most agree that only an insider to the culture portrayed in the book can sense if it is authentic (Howard 1991; Bishop 2003; Short and Fox 2003). This study enlisted insiders of the different cultures to review the books. Given the considerable influence of multicultural literature on outsiders of the culture as well as the self-image of children within the culture, ongoing evaluation of these books by insiders is essential. Additionally, this study offered multiple insider perspectives rather than a single perspective. Educators argue that no single insider perspective can be used to evaluate cultural authenticity. The evaluation of the books by multiple reviewers who were insiders of each culture added another layer to the methodological strength of this study in respect to inter-coder reliability and validity.

This study has many implications for librarians, educators, and authors of children's literature. Children's librarians who are developing collections should remember that no single book can reflect the variety of life experiences of even one cultural group. Furthermore, cultures are constantly growing and changing, and therefore the actions and behaviors that are currently deemed culturally authentic will also change. When a youth services librarian is confronted with the task of developing a new collection of multicultural literature or 
maintaining an established collection with a limited budget, the coding scheme developed for this study can be employed in selecting authentic books, in lieu of choosing any title that features a person of color out of sheer desperation for some semblance of diversity in the collection.

The design and findings of this study also present practical implications for educators as they design lessons that will shape the way in which children approach the reading of multicultural picture books. Educators should understand that literature is a fundamental way in which children learn about themselves and others. Culturally authentic books are more engaging for children from the culture portrayed and serve as a vital source of intercultural understanding. Even in cities where the population is relatively homogeneous, exposure to literature accurately portraying ethnic minorities is beneficial, as it aids children of all cultures in their understanding of others. The coding scheme proposed by this study will help educators evaluate literature empirically and avoid books with distorted images, text, and cultural values. Given our finding that stereotypes often exist alongside culturally authentic details and values, educators must also teach children to engage critically with the literature.

Some educators and librarians view the debate about cultural authenticity as a debate about social responsibility, in that authors of multicultural literature should use their creative imaginations and literary skills thoughtfully and cautiously when they write about characters, plots, and themes related to the specific cultural groups (Short and Fox 2003). By soliciting feedback from cultural insiders prior to publication, authors may be able to avoid, or at least minimize, the transmission of negative hidden messages. Some of the American Library Association (ALA)-affiliated organizations, such as APALA (Asian/Pacific American Librarians Association), Black Caucus of ALA, and REFORMA, can play an important role in this process.

While the current study developed a new approach to evaluate the cultural authenticity of picture books (i.e., systematic evaluation by multiple cultural insiders), our understanding of the specific criteria for assessing cultural authenticity is incomplete. It might be easier to evaluate the accuracy of cultural details than the underlying values. What aspects are to be considered when determining if a particular value is culturally authentic? Might it be possible for an outsider to evaluate the authenticity of a book if clear guidelines are available? Future research will need to further analyze and identify the criteria that cultural insiders use when assessing the authenticity of cultural values portrayed in literature. Findings of such research will assist in the refinement of collection development policies and will inform the practice of multicultural education. 
Appendix

Table Ar. List of Titles Selected for Evaluation

\begin{tabular}{|c|c|c|}
\hline Title & Author & Year \\
\hline \multicolumn{3}{|l|}{ African American titles: } \\
\hline Dear Mr. Rosenwald & Carole Boston Weatherford & 2006 \\
\hline Hot City & Barbara Joosse & 2004 \\
\hline Hot Day on Abbott Avenue & Karen English & 2004 \\
\hline Jackie's Bat & Marybeth Lorbiecki & 2006 \\
\hline Mim's Christmas Jam & Andrea David Pinkney & 2001 \\
\hline Night Boat to Freedom & Margot Theis Raven & 2006 \\
\hline One of the Problems of Everett Anderson & Lucille Clifton & 2001 \\
\hline Squashed in the Middle & Elizabeth Winthrop & 2005 \\
\hline Subway & Anastasia Suen & 2004 \\
\hline The Escape of Oney Judge & Emily Arnold McCully & 2007 \\
\hline The Hard-Times Jar & Ethel Footman Smothers & 2003 \\
\hline The Journey of Oliver K. Woodman & Darcy Pattison & 2003 \\
\hline Visiting Day & Jacqueline Woodson & 2002 \\
\hline Wind Flyers & Angela Johnson & 2007 \\
\hline Yo, Jo! & Rachel Isadora & 2007 \\
\hline \multicolumn{3}{|l|}{ Asian American titles: } \\
\hline Apple Pie 4 th of July & Janet S. Wong & 2002 \\
\hline Bee-bim Bop & Linda Sue Park & 2005 \\
\hline Behind the Mask & Yangsook Choi & 2006 \\
\hline Bringing in the New Year & Grace Lin & 2008 \\
\hline Cooper's Lesson & Sun Yung Shin & 2004 \\
\hline Every Year on Your Birthday & Rose Lewis & 2007 \\
\hline Grandfather Counts & Andrea Cheng & 2000 \\
\hline Just Add One Chinese Sister & Patricia MacMahon & 2005 \\
\hline Landed & Milly Lee & 2006 \\
\hline My Mei Mei & Ed Young & 2006 \\
\hline Red Is a Dragon & Roseanne Thong & 2001 \\
\hline Round Is a Mooncake & Roseanne Thong & 2000 \\
\hline Sixteen Years in Sixteen Seconds & Paula Yoo & 2005 \\
\hline Uncle Peter's Amazing Chinese Wedding & Lenore Look & 2004 \\
\hline Yoko Writes Her Name & Rosemary Wells & 2008 \\
\hline \multicolumn{3}{|l|}{ Hispanic American Titles: } \\
\hline A Box Full of Kittens & Sonia Manzano & 2007 \\
\hline Featherless & Juan Felipe Herrera & 2004 \\
\hline If the Shoe Fits & Gary Soto & 2002 \\
\hline Let's Eat! & Pat Mora & 2008 \\
\hline Little Mama Forgets & Robin Cruise & 2006 \\
\hline My Feet Are Laughing & Lissette Norman & 2006 \\
\hline My Grandma & Ginger Foglesong Guy & 2007 \\
\hline My Little Car & Gary Soto & 2006 \\
\hline Nana's Big Surprise & Amada Irma Perez & 2007 \\
\hline No Dogs Allowed! & Sonia Manzano & 2004 \\
\hline Oh, Brother! & Nikki Grimes & 2008 \\
\hline Quinito's Neighborhood & Ina Cumpiano & 2005 \\
\hline Roberto Clemente & Jonah Winter & 2005 \\
\hline Sparky's Bark & Mimi Chapra & 2006 \\
\hline The Bakery Lady & Pat Mora & 2001 \\
\hline
\end{tabular}




\section{References}

Barksdale-Ladd, Mary Alice, and Bena R. Hefflin. 2001. “African American Children's Literature That Helps Students Find Themselves: Selection Guidelines for Grades K-3.” Reading Teacher 54 (8): 81019.

Barrera, Rosalinda B., and Ruth E. Quiroa. 2003. “The Use of Spanish in Latino Children's Literature in English: What Makes for Cultural Authenticity?” In Stories Matter: The Complexity of Cultural Authenticity in Children's Literature, edited by Dana L. Fox and Kathy G. Short. Urbana, IL: National Council of Teachers of English.

Bishop, Rudine S. 1997. "Selecting Literature for a Multicultural Curriculum.” In Using Multiethnic Literature in the K-8 Classroom, edited by Violet J. Harris. Norwood, MA: Christopher-Gordon.

Bishop, Rudine S. 2003. "Reframing the Debate about Cultural Authenticity." In Stories Matter: The Complexity of Cultural Authenticity in Children's Literature, edited by Dana L. Fox and Kathy G. Short. Urbana, IL: National Council of Teachers of English.

Cai, Mingshi, and Rudine S. Bishop. 1994. "Multicultural Literature for Children: Toward a Clarification of the Concept." In The Need for Story: Cultural Diversity in Classroom and Community, edited by Anne H. Dyson and Celia Genishi. Urbana, IL: National Council of Teachers of English.

Daly, Emily. 2004. "Valuing Readers' Life Experiences: Culturally Sensitive African American Children's Literature." Current Studies in Librarianship 28 (1): 5-17.

Guevara, Susan. 2003. “Authentic Enough: Am I? Are You? Interpreting Culture for Children's Literature.” In Stories Matter: The Complexity of Cultural Authenticity in Children's Literature, edited by Dana L. Fox and Kathy G. Short. Urbana, IL: National Council of Teachers of English.

Harada, Violet H. 1995. "Issues of Ethnicity, Authenticity, and Quality in Asian American Picture Books, 1983-93." Journal of Youth Services in Libraries 8 (2): 135-49.

Howard, E. F. 1991. "Authentic Multicultural Literature for Children: An Author's Perspective.” In Multicolored Mirror: Cultural Substance in Literature for Children and Young Adults, edited by Merri Lindgren. Fort Atkinson, WI: Highsmith.

Jewett, Pamela. 2011. “'Some People Do Things Different from Us': Exploring Personal and Global Cultures in a First Grade Classroom.” Journal of Children's Literature 37 (1): 20-29.

Knowles, Liz, and Martha Smith. 2007. Understanding Diversity through Novels and Picture Books. Westport, CT: Libraries Unlimited.

Mendoza, Jean, and Debbie Reese. 2001. "Examining Multicultural Picture Books for the Early Childhood Classroom: Possibilities and Pitfalls." Early Childhood Research and Practice 3 (2). http://ecrp.uiuc .edu/v3n2/mendoza.html.

Mo, Weimin, and Wenju Shen. 1997. "Reexamining the Issue of Authenticity in Picture Books." Children's Literature in Education 28 (2): 85-93.

Mo, Weimin, and Wenju Shen. 2003. "Accuracy Is Not Enough: The Role of Cultural Values in the Authenticity of Picture Books." In Stories Matter: The Complexity of Cultural Authenticity in Children's Literature, edited by Dana L. Fox and Kathy G. Short. Urbana, IL: National Council of Teachers of English.

Nilsson, Nina L. 2005. "How Does Hispanic Portrayal in Children's Books Measure Up after 40 Years? The Answer Is 'It Depends.'” Reading Teacher 58 (6): 534-48.

Rochman, Hazel. 2003. "Beyond Political Correctness." In Stories Matter: The Complexity of Cultural Authenticity in Children's Literature, edited by Dana L. Fox and Kathy G. Short. Urbana, IL: National Council of Teachers of English. 
Short, Dana L., and Kathy G. Fox. 2003. "The Complexity of Cultural Authenticity in Children's Literature: Why the Debates Really Matter." In Stories Matter: The Complexity of Cultural Authenticity in Children's Literature, edited by Dana L. Fox and Kathy G. Short. Urbana, IL: National Council of Teachers of English.

Smith-D'Arezzo, Wendy M., and Margaret Musgrove. 2011. "Two Professors Critique the Representations of Africans and African Americans in Picture Books." Equity and Excellence in Education 44 (2): 188202.

Yokota, Junko. 2009. "Asian Americans in Literature for Children and Young Adults.” Teacher Librarian 36 (3): $15-19$.

EunYoung Yoo-Lee: associate professor in the School of Library and Information Sciences, North Carolina Central University. Yoo-Lee received her PhD in library and information studies from University of Wisconsin-Madison and her MA in journalism and mass communications from Sogang University, Seoul, Korea. She was a recipient of an ALA Diversity Research Grant. Her research areas include human information behaviors in diverse contexts, digital library and social media use, consumer health informatics, and diversity education. Her current research focuses on Hispanic Americans' and Asian Americans' health information needs and health information behavior in the e-health environment. E-mail (corresponding author): eunyoung@nccu.edu.

Lauren Fowler: electronic resources and serials management librarian, Caldwell College. Before this position, Fowler worked in the Office for Copyright and Scholarly Communications at Duke University Libraries. She received her master of library science from North Carolina Central University in 2012, a master of arts in anthropology from the University of Pittsburgh in 2010, and a bachelor of arts in anthropology and English from the University of Notre Dame in 2008. Her research interests include user-centered service, copyright and fair use in the academic environment, and massive open online courses. E-mail: Ifowler@caldwell.edu.

Denice Adkins: associate professor, University of Missouri-Columbia School of Information Science and Learning Technologies, immediate past-president of REFORMA, the National Association to Promote Library and Information Services to Latinos and the Spanish-speaking, and Fulbright Scholar to Honduras, 2008. Her research emphasizes library service to Latinos and service to children, with focus on bilingual children's materials; leisure reading and genre fiction; public libraries; community demographics; and geographic information systems. Her current research looks at professional presentations of diversity. E-mail: adkinsde@missouri.edu.

Kyung-Sun Kim: associate professor in the School of Library and Information Studies, University of Wisconsin-Madison. Kim holds a PhD from the University of Texas at Austin and an MLIS from the Université de Montréal, Canada. Her research focuses on information behavior, user-centered systems and services for diverse users, and information equity. Her current research is on use of information sources including social media, and information literacy. She has published in Library Quarterly, Library and Information Science Research, Information Processing and Management, Journal of Information Science, and elsewhere. E-mail: kskim@slis.wisc.edu.

Halima N. Davis: library manager and youth services librarian, Dr. Clarence V. Cuffee Library, Chesapeake, VA. Davis earned her BA from University of Maryland Eastern Shore and an MLS from 
North Carolina Central University. She was a recipient of the IMLS Diversity Grant, as well as the ALA Spectrum Scholarship. She is involved in the selection of children's materials for her branch and is very interested in providing culturally authentic materials to the patrons she serves. Her research interests are preservation of tropical collections and library services in developing countries. E-mail: hadavis@infopeake.org. 